\title{
Article
}

\section{Genotyping of STR and DIP-STR Markers in Plasma Cell-Free DNA for Simple and Rapid Noninvasive Prenatal Diagnosis of Zygosity of Twin Pregnancies}

\author{
Agnieszka Dziennik ${ }^{1}$, Krzysztof Preis ${ }^{2}$, Małgorzata Świątkowska-Freund ${ }^{2}$ and Krzysztof Rębała ${ }^{1}$ \\ ${ }^{1}$ Department of Forensic Medicine, Medical University of Gdańsk, Gdańsk, Poland and ${ }^{2}$ Department of Obstetrics, Medical University of Gdańsk, Gdańsk, Poland
}

\begin{abstract}
Due to the high rate of complications, special medical care must be provided especially for monozygotic twin pregnancies, which are characterized as having 2.5 times higher mortality of fetuses. In recent years, examination of cell-free DNA (cfDNA) circulating in maternal plasma has become a useful noninvasive method of prenatal diagnosis. However, fetal DNA constitutes only 3-20\% of plasma cfDNA during pregnancy. Short tandem repeats (STRs) are routinely used in forensic examination of DNA mixtures and are able to identify $5 \%$ minority components. Haplotypes of deletion/insertion polymorphisms and STRs (DIP-STRs) are able to detect even $0.1 \%$ minority components of DNA mixtures. Thus, STRs and DIP-STRs seem to be a perfect tool for detection of fetal alleles in DNA isolated from maternal plasma. Here, we present a novel noninvasive prenatal diagnosis technique of determination of pregnancy zygosity based on examination of feto-maternal microchimerism of plasma cfDNA with the use of STRs and DIP-STRs. Our preliminary results based on 22 STR loci showed 67\% sensitivity, $100 \%$ specificity and $82 \%$ accuracy for prenatal detection of twin dizygosity. The corresponding values for seven DIP-STRs were $13 \%, 100 \%$ and 54\%, respectively. Owing to assay performance, low DNA input requirements, low costs (below 10 USD per patient) and simplicity of analysis, genotyping of STR/DIP-STR markers in maternal plasma cfDNA may become a useful supplementary test for noninvasive prenatal diagnosis of twin zygosity in cases when chorionicity and zygosity cannot be reliably determined by ultrasound examination and prognostic value may be provided by a DNA test determining pregnancy zygosity.
\end{abstract}

Keywords: Twin pregnancy; prenatal diagnosis; twin zygosity; plasma cell-free DNA; short tandem repeats (STRs); deletion and insertion polymorphism (DIP)

(Received 1 June 2019; accepted 10 September 2019; First published online 17 October 2019)

Twin pregnancy is a common phenomenon. According to Hellin's law discovered in 1895, it used to occur, on average, once per 80 births (Gall, 1996). Later studies revealed strong variation in frequency of twin births among different populations. The lowest twinning rate of less than $0.9 \%$ is found in populations of South America and East, Southeast and South Asia, whereas the highest values of more than $1.8 \%$ are characteristic of many African populations (Smits \& Monden, 2011). The frequency of twin pregnancies in developed countries of Europe, Oceania and North America used to fall in between, but it has grown dramatically over the last four decades, reaching values observed in sub-Saharan Africa (Pison \& D'Addato, 2006; Pison et al., 2015). The increase of occurrence of twin pregnancies is assumed to result from a shift in age at first reproduction (the share of twin pregnancies grows with the age of a mother) and from more and more common use of assisted reproduction technology (Blickstein et al., 1999; Doyle, 1996; Wimalasundera \& Fisk, 2002).

Twin pregnancies are classified as dizygotic (DZ; resulting from fertilization of two ova by two sperms) and monozygotic (MZ;

Author for correspondence: Krzysztof Rębała, Email: k.rebala@gumed.edu.pl

Cite this article: Dziennik A, Preis K, Świątkowska-Freund M, and Rębała K. (2019) Genotyping of STR and DIP-STR Markers in Plasma Cell-Free DNA for Simple and Rapid Noninvasive Prenatal Diagnosis of Zygosity of Twin Pregnancies. Twin Research and Human Genetics 22: 321-329, https://doi.org/10.1017/thg.2019.89 resulting from division of an embryo to two identical embryonic structures within the first 14-16 days from fertilization of one ovum by one sperm; Benson \& Doubilet, 1991; Golan et al., 1981; Machin, 1993). In European populations, MZ and DZ pregnancies constitute $30 \%$ and $70 \%$ of twin pregnancies, respectively (Blickstein et al., 1999; Machin, 1993). While pharmacological ovarian stimulation and multiple embryo transfer are related to higher frequency of polyzygotic pregnancies, in vitro technology is suspected to provoke later divisions of embryos due to manipulation of the zona pellucida (Blickstein et al., 1999; Derom et al., 1987; Edwards et al., 1986).

Multiple pregnancies, including twin pregnancies, are regarded as pathological in humans as far as they are related to 4-10 times higher rates of complications (including fatal outcomes) for a pregnant woman and for fetuses (Baldwin, 1994; Campbell, 2000). Thus, they require special medical care during pregnancy. It concerns especially MZ twin pregnancies, which are characterized by at least 2.5 times higher mortality of fetuses (Landy \& Nies, 1995; Monteagudo et al., 1994), mainly due to twin-to-twin transfusion syndrome (TTTS) in monochorionic diamniotic pregnancies, which constitute about two-thirds of MZ twin pregnancies (Simpson \& Miller, 2018).

In recent years, testing of cell-free DNA (cfDNA) circulating in the plasma of pregnant women has become another, besides 
ultrasound examination, very useful, noninvasive method of prenatal screening, which is safe for both the mother and the fetus (Allyse et al., 2012; Lo, 2008; Lo, Hjelm et al., 1998; Mujezinovic \& Alfirevic, 2007; Wright \& Burton, 2008). Apoptosis of placental cells leads to the presence of placental DNA in the mother's bloodstream (Faas et al., 2012; Flori et al., 2004; Hochstenbach et al., 2015), which is known as feto-maternal microchimerism (Evans et al., 1999; Lo, Tien et al., 1998; Tjoa et al., 2006). The content of placental DNA, commonly referred to in plasma cfDNA studies as fetal DNA, increases with gestational age, and according to various authors, it may constitute on average $3-10 \%$ of cfDNA circulating in plasma in early pregnancy and 6-20\% of cfDNA in late pregnancy (Lo, Tien et al., 1998; Lun et al., 2008; Wang et al., 2013).

Microsatellites, commonly known as short tandem repeats (STRs), constitute genome fragments with a variable number of tandem repeats of short repetitive units of 1-6 bp (Butler, 2012). Due to a high level of polymorphism, these markers have found wide applications in forensic medicine for genetic human identification (Gill et al., 1994; Jobling \& Gill, 2004; Moretti et al., 2001). Capillary electrophoresis is a technique used routinely in forensic genetics for separation and detection of STRs and enables differentiation of alleles differing in size by only one nucleotide. A significant number of observed alleles makes STR markers a perfect tool for analysis and differentiation of DNA mixtures coming from at least two individuals, which suggests their potential usefulness in detecting fetal alleles in the case of feto-maternal microchimerism.

Deletion/insertion polymorphism-STR (DIP-STR) markers constitute haplotypes comprising two polymorphic regions: deletion or insertion (DIP) and a microsatellite. In the case of DIP-STR markers, one of the primers recognizes a sequence complementary to deletion or insertion so that only an allele with deletion (S) or insertion (L) is amplified. In comparison to standard analysis of STR polymorphism, analysis of DIP-STR markers enables detection of an allele of a subject whose DNA constitutes a minority component in the mixture of DNA from two subjects, even if the content of this subject's DNA is very low (Castella et al., 2013; Cereda et al., 2014; Oldoni et al., 2015). One or two DIP-STR alleles of the minority component of highly unbalanced DNA mixtures can be identified when the major DNA contributor is DIP homozygous (SS or LL) and the minor DNA contributor is DIP heterozygous (SL), or when the major and minor DNA contributors are opposite DIP homozygous (SS/LL or LL/SS). When the minor DNA contributor has no unique $\mathrm{S}$ or $\mathrm{L}$ allele, DIP-STR typing of DNA mixtures resembles standard STR typing. Owing to the ability to detect alleles of the minority component in highly unbalanced DNA mixtures, DIP-STRs seem to be an even better tool for the detection of fetal alleles in DNA isolated from the plasma of pregnant women.

Every child inherits one allele from its mother and one from its father. The plasma of women with singleton pregnancies should contain one additional STR or DIP-STR allele inherited from a father, assuming that it is different to maternal alleles. Thus, detection of two additional nonmaternal STR or DIP-STR alleles in a plasma sample of a pregnant woman indicates a DZ twin pregnancy. The aim of our study was to assess usefulness of genotyping of STR and DIP-STR polymorphism in maternal plasma cfDNA as a cost-effective supplementary test for noninvasive prenatal diagnosis of twin zygosity in cases when chorionicity and zygosity cannot be reliably determined by ultrasound examination and a prognostic value may be provided by a DNA test determining pregnancy zygosity.

\section{Materials and Methods}

\section{Materials}

Samples from 28 twin pregnancies, obtained from the patients of the Department of Obstetrics at the Medical University of Gdańsk and from the patients of the Department of Obstetrics and Gynaecology at the St. Adalbert Hospital in Gdańsk, Copernicus Podmiot Leczniczy Sp. z o.o., were used in the study. For additional comparison of the amount of fetal DNA in singleton and twin pregnancies, samples from 15 singleton pregnancies with a male fetus were used. Samples of $3 \mathrm{~mL}$ of peripheral blood were collected from pregnant women (23-41 weeks of gestation, age: $22-46$ years) into BD Vacutainer Plus Blood Collection Tubes (BD, Plymouth, $\mathrm{UK})$ with $\mathrm{K} 3$-EDTA and stored at $2-8{ }^{\circ} \mathrm{C}$ for further processing. All samples of maternal peripheral blood were divided into two portions: 0.6 and $2.4 \mathrm{~mL}$. The first portion $(0.6 \mathrm{~mL})$ was stored at $-20^{\circ} \mathrm{C}$ as reference material for determination of maternal DNA profile, while the remaining part $(2.4 \mathrm{~mL})$ was centrifuged within $8 \mathrm{~h}$ of sampling (Barrett et al., 2011) in order to separate plasma (10 min at $1600 \times \mathrm{g})$. The obtained plasma was centrifuged again in order to separate the remaining cell components (10 min at 16,000 × g; Ying et al., 2004). Immediately after delivery, about $1.5 \mathrm{~mL}$ of umbilical cord blood was collected from each twin (56 samples in total) from the side of placenta after removal of the umbilical cord and stored at $-20^{\circ} \mathrm{C}$ until the time of DNA isolation. The study was approved by the Independent Bioethics Commission for Research at the Medical University of Gdańsk, and all patients provided their informed written consent for participation in the study.

\section{DNA Isolation and Measurement of DNA Concentration}

cfDNA was isolated from plasma with the use of QIAamp DSP Virus Spin Kit (Qiagen, Hilden, Germany) in accordance with the manufacturer's manual, while DNA from maternal whole peripheral blood (the frozen portions of $0.6 \mathrm{~mL}$ ) and from umbilical cord blood was isolated with the use of a nonenzymatic method (Lahiri \& Nurnberger, 1991). Concentration of total human and male DNA isolated from plasma samples for singleton and twin pregnancies was measured by quantitative polymerase chain reaction (qPCR) with the use of Plexor HY assay (Promega; sensitivity $>0.0064 \mathrm{ng} / \mu \mathrm{L}$ ) and 7900HT Fast Real-Time PCR System (Applied Biosystems, Foster City, CA, USA). Concentration of DNA isolated from whole peripheral blood and umbilical cord blood was measured spectrophotometrically with the use of ND-1000 spectrophotometer (NanoDrop Technologies, Rockland, DE, USA; sensitivity $>0.5 \mathrm{ng} / \mu \mathrm{L}$ ).

\section{Amplification of STR and DIP-STR Markers}

Commercial PowerPlex Fusion kit (Promega, Madison, WI, USA) was used to analyze polymorphism of 22 autosomal STRs (D1S1656, D2S441, D2S1338, D3S1358, D5S818, D7S820, D8S1179, D10S1248, D12S391, D13S317, D16S539, D18S51, D19S433, D21S11, D22S1045, CSF1PO, FGA, Penta D, Penta E, TH01, TPOX, vWA), one Y-chromosomal STR (DYS391) and a sex marker (amelogenin), with primers labeled with four different fluorescent dyes. PCR was conducted in Mastercycler Gradient thermal cycler (Eppendorf, Hamburg, Germany) in the total volume of $5 \mu \mathrm{L}$, containing $1 \mathrm{ng}$ of genomic DNA from whole peripheral/ umbilical cord blood or $1 \mathrm{ng}$ of cfDNA isolated from plasma. For low cfDNA concentrations $(<0.4 \mathrm{ng} / \mu \mathrm{L})$, in order to allow addition of $1 \mathrm{ng}$ of cfDNA to the reaction, the total volume of reaction mixture was increased to $10 \mu \mathrm{L}$. Except for the aforementioned modifications, 
Table 1. DIP-STR markers used in the study

\begin{tabular}{|c|c|c|c|c|c|c|}
\hline Marker & $\begin{array}{l}\text { STR size } \\
\text { (bp) }\end{array}$ & $\begin{array}{l}\text { Chromosomal } \\
\text { location }\end{array}$ & $\begin{array}{c}\text { Fluorescent } \\
\text { label }\end{array}$ & $\begin{array}{l}\text { Allele size range } \\
\text { (bp) }\end{array}$ & $\begin{array}{c}\text { Primer concentration in } \\
\text { multiplex } S(\mu M)\end{array}$ & $\begin{array}{c}\text { Primer concentration in } \\
\text { multiplex } L(\mu M)\end{array}$ \\
\hline Amelogenin & - & $X, Y$ & 6-FAM & $106-112$ & 0.04 & 0.04 \\
\hline rs34212659-STR & 4 & 7 & $6-F A M$ & $182-194$ & 0.16 & 0.12 \\
\hline rs142543564-STR & 4 & 2 & $6-F A M$ & $210-234$ & 0.4 & 0.3 \\
\hline rs35032587-STR & 4 & 15 & 6-FAM & $239-271$ & 0.08 & 0.24 \\
\hline rs60194384-STR & 4 & 15 & $6-F A M$ & $281-309$ & 2.4 & 0.9 \\
\hline rs2308142-STR & 3 & 20 & VIC & $213-231$ & 0.18 & 0.3 \\
\hline rs145423446-STR & 4 & 16 & VIC & $234-256$ & 0.08 & 0.08 \\
\hline rs111478323-STR & 4 & 2 & PET & $240-260$ & 0.2 & 0.12 \\
\hline
\end{tabular}

DNA amplification performed with the use of PowerPlex Fusion kit was carried out in accordance with the manufacturer's manual.

DIP-STR polymorphism was analyzed with the use of two homemade multiplex PCR systems, developed separately for amplification of deletion alleles (S) and insertion alleles (L). The analysis included DIP-STR markers with tri- and tetranucleotide repeats described so far (Castella et al., 2013; Oldoni et al., 2015), rejecting dinucleotide markers due to high stutter ratio and resulting difficulties in interpreting DNA mixtures. While designing multiplex systems, a possibility of primer dimer formation (by AutoDimer software; Vallone \& Butler, 2004) and of overlapping of allele size ranges was verified. From each pair of markers with primers forming dimers, a marker with higher polymorphism (higher observed heterozygosity) was selected. Primers with overlapping allele size ranges were labeled with different fluorescent dyes. The last stage of multiplex design involved rejection of DIP-STR markers whose primers generated numerous nonspecific products, that is, rs71070706-STR, rs72406828-STR and rs146332920-STR, when added to the reaction mixture. Finally, each developed multiplex included seven DIP-STR markers and the amelogenin locus as the sex marker (Table 1).

For both homemade DIP-STR multiplex systems, PCR was conducted with the use of Multiplex PCR Plus Kit (Qiagen) in GeneAmp PCR System 9700 thermal cycler (Applied Biosystems) in the total volume of $5 \mu \mathrm{L}$ containing $1 \mathrm{ng}$ of genomic DNA from peripheral/ umbilical cord blood or $1 \mathrm{ng}$ of cfDNA isolated from plasma and primers with the final concentrations presented in Table 1 . The $5^{\prime}$ ends of forward primers were labeled with three different fluorescent dyes (Table 1 ). For low cfDNA concentrations $(<0.4 \mathrm{ng} / \mu \mathrm{L})$, in order to allow addition of $1 \mathrm{ng}$ of cfDNA to the reaction, the total volume of reaction mixture was increased to $10 \mu \mathrm{L}$. The thermal profile included $5 \mathrm{~min}$ of initial denaturation at $95^{\circ} \mathrm{C}, 30$ cycles of amplification $\left(1 \mathrm{~min}\right.$ at $94^{\circ} \mathrm{C}, 1 \mathrm{~min}$ at $62^{\circ} \mathrm{C}, 1 \mathrm{~min}$ at $72^{\circ} \mathrm{C}$ ) and $60 \mathrm{~min}$ of final elongation at $72{ }^{\circ} \mathrm{C}$.

\section{Capillary Electrophoresis of Amplification Products}

A total of $9 \mu \mathrm{L}$ of Super-DI Formamide (MCLAB, South San Francisco, CA, USA) were supplemented with $1 \mu \mathrm{L}$ of amplification products and with $0.4 \mu \mathrm{L}$ of ILS 500 size standard (Promega) for PowerPlex Fusion kit or $0.4 \mu \mathrm{L}$ of Orange DNA Size Standard (MCLAB) for DIP-STR multiplexes. The samples were denatured for $2 \mathrm{~min}$ at $95^{\circ} \mathrm{C}$ and immediately cooled for $3 \mathrm{~min}$ on ice. Subsequently, PCR products were injected for $5 \mathrm{~s}$ at $3 \mathrm{kV}$ and separated by capillary electrophoresis at $60^{\circ} \mathrm{C}$ and
$15 \mathrm{kV}$ in 3130 Genetic Analyzer (Applied Biosystems) with the use of NanoPOP-4 polymer (MCLAB) and a $36-\mathrm{cm} 4$-capillary array. Genotypes of the analyzed samples were determined with the use of GeneMapper ID software v3.2 (Applied Biosystems) by comparison to an allelic ladder in case of PowerPlex Fusion kit or to a CEPH 1347-02 reference sample (Applied Biosystems) with a known, published DIP-STR genotype (Castella et al., 2013; Oldoni et al., 2015).

\section{Statistical Analysis}

Male DNA fraction in plasma cfDNA was calculated as a ratio of male DNA concentration and total human DNA concentration, measured by qPCR. A nonparametric Mann-Whitney $U$ test was carried out using STATISTICA 12 software (StatSoft, Tulsa, OK, USA) to test for differences between STR and DIP-STR markers in their ability to detect fetal alleles in maternal plasma and to correctly diagnose dizygosity. The same software was employed to assess correlation between the fraction of male DNA in plasma cfDNA and the number of STR or DIP-STR markers with at least one detected fetal allele.

\section{Results}

At least one fetal STR allele was observed in each of 28 plasma samples obtained from women with twin pregnancies. In case of DIP-STR markers, two pregnancies (7.1\%) revealed no fetal alleles. On the average, fetal alleles were detected in $37.2 \%$ (range: 4.5-68.2\%) and 39.3\% (range: $0-71.4 \%$ ) of the tested 22 STRs and 7 DIP-STRs per twin pregnancy, respectively. Control DNA samples of the umbilical cord blood from twins coming from 28 pregnancies showed 15 twin-pairs with different genotypes (DZ pregnancies, 53.6\%) and 13 twin-pairs with identical genotypes (MZ pregnancies, $46.4 \%$ ). In case of MZ pregnancies, blood plasma collected during pregnancy always contained at most one additional STR or DIP-STR allele in comparison to maternal DNA profile obtained from peripheral blood. In case of DZ pregnancies, two additional nonmaternal alleles, clearly indicating DZ twin pregnancy, were detected in 10 plasma samples $(66.7 \%)$ for STRs and in 2 plasma samples (13.3\%) for DIP-STRs. Both twin pregnancies identified as DZ by DIP-STR typing of plasma cfDNA were also identified as DZ by STR typing. Examples of DNA profiles indicative of DZ twin pregnancy for STR and DIP-STR are shown in Figures 1 and 2.

In order to compare which polymorphic markers, STRs or DIP-STRs, are more robust to detect twin pregnancy dizygosity, 
Fig. 1. STR typing of cfDNA from maternal plasma, indicating DZ twin pregnancy, collated with DNA profiles of the mother and two twins (results for marker TH01 from PowerPlex Fusion kit). Two higher peaks correspond to maternal alleles (6 and 8 ), which were also observed in DNA extracted from maternal peripheral blood (genotype of a mother: 6,8). Two lower peaks correspond to fetal alleles ( 7 and 9.3), which were later detected in umbilical cord blood samples of twins after the birth (genotypes of twins: 7,8 and 6,9.3). Detection of fetal DNA by STR typing is possible when it constitutes at least $5 \%$ of cfDNA.
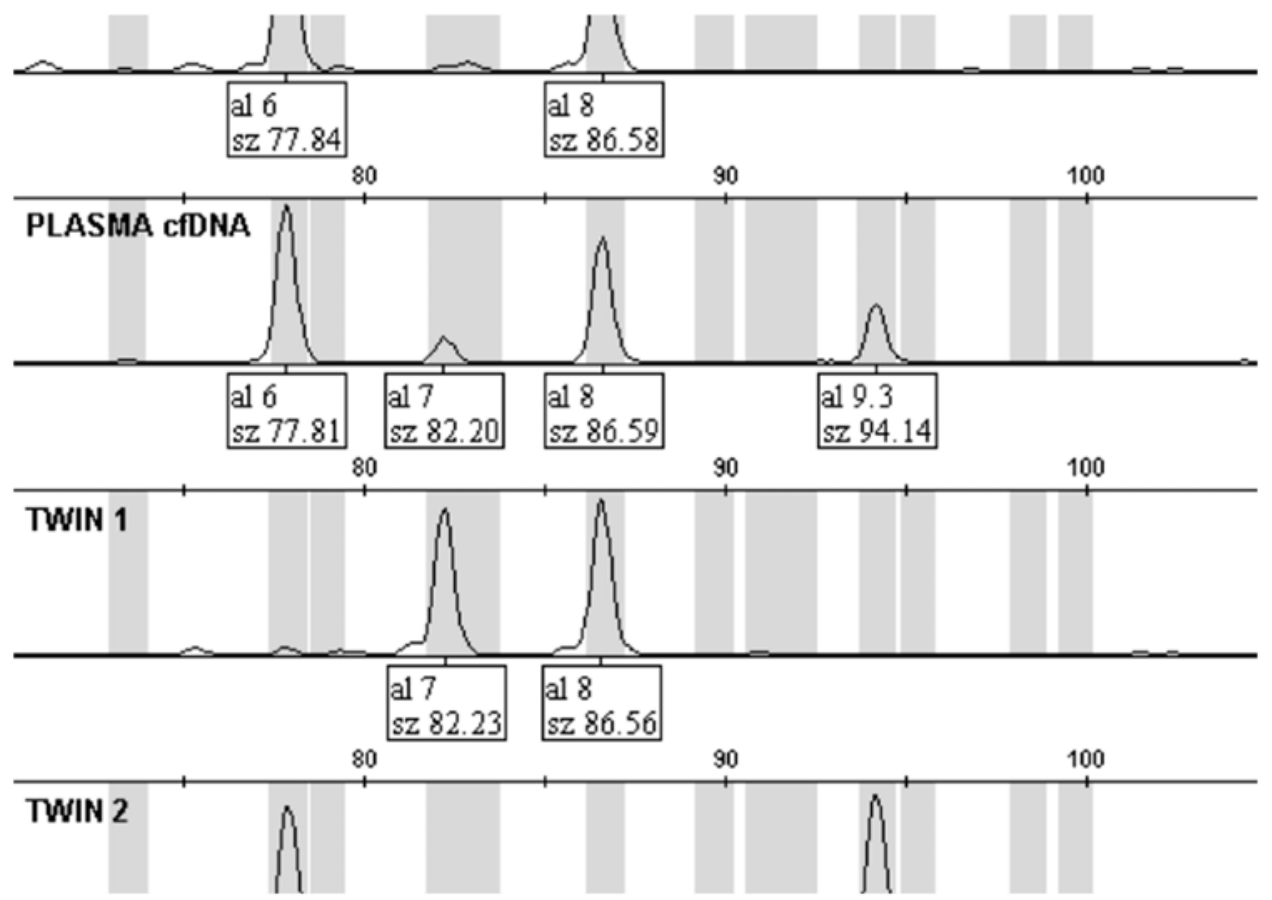

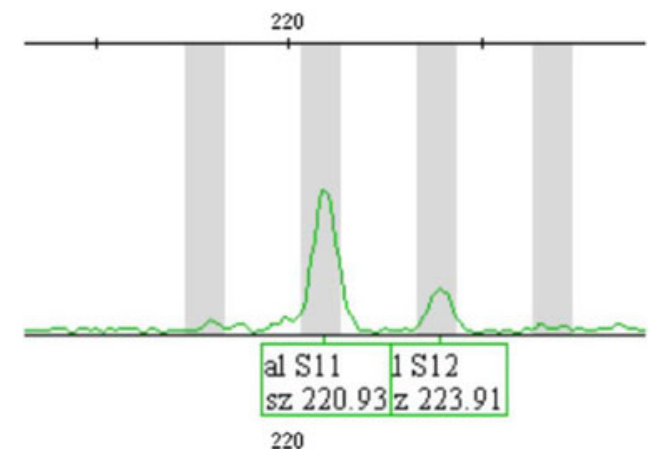

220

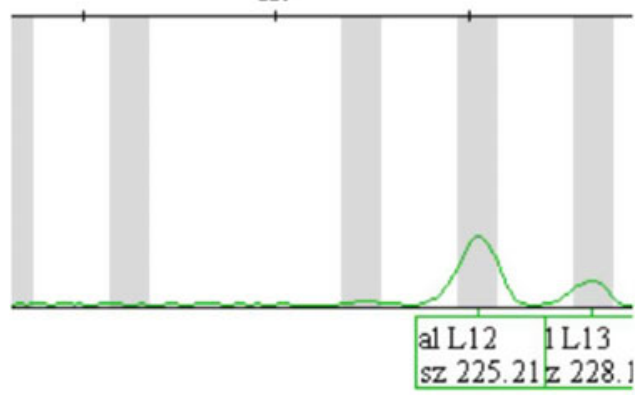

Fig. 2. DIP-STR typing of cfDNA from maternal plasma, indicating DZ twin pregnancy (a result for marker rs2308142-STR). The upper panel shows maternal alleles (S11 and S12) amplified by a multiplex PCR system for analysis of alleles with deletion (S alleles), which were also observed in DNA extracted from maternal peripheral blood (genotype of a mother: S11,S12). The lower panel shows fetal alleles (L12 and L13) amplified by a multiplex PCR system for analysis of alleles with insertion (L alleles), which were later detected in umbilical cord blood samples of twins after the birth (genotypes of twins: S12,L12 and S12,L13). As S and $L$ alleles are amplified by different primer pairs in two separate multiplex PCR systems, detection of fetal DNA in this case is possible even when it constitutes only $0.1 \%$ of cfDNA.

we counted for each marker the number and percent of twin pregnancies in which at least one fetal allele was detected, and the number and percent of DZ twin pregnancies, in which two fetal alleles (indicating dizygosity of pregnancy) were detected (Table 2).
No statistically significant differences between STRs and DIP-STRs were observed in the ability to detect fetal alleles in plasma cfDNA (37.2\% vs. $39.3 \%$ of twin pregnancies, on average, respectively; Mann-Whitney $U$ test: $p=.57$ ). Fetal alleles in plasma cfDNA were the most frequently observed for D12S391 (78.6\% of twin pregnancies), and the least frequently for D5S818 and TPOX (7.1\% of twin pregnancies). Among DIP-STRs, the most useful marker to detect fetal alleles in plasma cfDNA was rs2308142-STR (53.6\% of twin pregnancies), while the least useful one was rs111478323-STR (25.0\% of twin pregnancies). Similarly, no statistically significant differences between STRs and DIP-STRs were observed in the ability to detect DZ pregnancy (5.5\% vs. $2.9 \%$ of twin pregnancies, on average, respectively; Mann-Whitney $U$ test: $p=.67$ ). Two fetal alleles indicating DZ pregnancy were observed the most frequently for D8S1179 and D12S391 (26.7\% of DZ twin pregnancies). rs2308142-STR also appeared to be the most useful marker to detect dizygosity among DIP-STRs $(13.3 \%$ of DZ twin pregnancies).

The mean concentration of cfDNA isolated from plasma was $0.56 \mathrm{ng} / \mu \mathrm{L}$ for twin pregnancies and $0.38 \mathrm{ng} / \mu \mathrm{L}$ for singleton pregnancies. For twin pregnancies with female fetuses, DNA concentration measurement by qPCR did not show presence of male DNA in any of the plasma samples. For singleton or twin pregnancies with at least one male fetus, male DNA constituted on average $6.0 \%$ of total cfDNA (range: $0.6-20.9 \%$ ), corresponding to the mean concentration of male DNA equal to $0.031 \mathrm{ng} / \mu \mathrm{L}$. A significantly higher fraction of fetal DNA (corresponding to male DNA measured by qPCR in pregnancies without female fetuses) was observed in twin pregnancies with two male fetuses $(9.3 \%$ on average) in comparison with singleton pregnancies with one male fetus (4.6\% on average; the Mann-Whitney $U$ test: $p=.04$ ).

No correlation between the fraction of male DNA in plasma cfDNA and the number of STR markers that showed presence of at least one fetal allele was observed for 10 twin pregnancies with two male fetuses, regardless of their zygosity $\left(R^{2}=.36, p=.07\right)$, and for 5 twin pregnancies with one male fetus $\left(R^{2}=.75, p=.06\right)$, 
Table 2. Comparison of the tested STR and DIP-STR markers in their ability to detect fetal alleles in maternal plasma cfDNA and to detect dizygosity of twin pregnancy

\begin{tabular}{|c|c|c|c|}
\hline Polymorphism & Marker & $\begin{array}{l}\text { Number and percent of twin pregnancies, } \\
\text { in which at least one fetal allele was } \\
\text { detected in maternal plasma cfDNA } \\
\qquad(N=28)\end{array}$ & $\begin{array}{l}\text { Number and percent of DZ twin } \\
\text { pregnancies, in which two fetal alleles } \\
\text { (indicating dizygosity of pregnancy) were } \\
\text { detected in maternal plasma } \\
\text { cfDNA }(N=15)\end{array}$ \\
\hline \multirow[t]{22}{*}{ STR } & D1S1656 & $12(43 \%)$ & $1(7 \%)$ \\
\hline & D2S441 & $9(32 \%)$ & 0 \\
\hline & D2S1338 & $12(43 \%)$ & 0 \\
\hline & D3S1358 & $20(71 \%)$ & $2(13 \%)$ \\
\hline & D5S818 & $2(7 \%)$ & 0 \\
\hline & D7S820 & $8(29 \%)$ & 0 \\
\hline & D8S1179 & $18(64 \%)$ & $4(27 \%)$ \\
\hline & D10S1248 & $5(18 \%)$ & 0 \\
\hline & D12S391 & $22(79 \%)$ & $4(27 \%)$ \\
\hline & D13S317 & $3(11 \%)$ & 0 \\
\hline & D16S539 & $20(71 \%)$ & 0 \\
\hline & D18S51 & $19(68 \%)$ & $2(13 \%)$ \\
\hline & D19S433 & $7(25 \%)$ & 0 \\
\hline & D21S11 & $13(46 \%)$ & $1(7 \%)$ \\
\hline & D22S1045 & $3(11 \%)$ & 0 \\
\hline & CSF1PO & $5(18 \%)$ & 0 \\
\hline & FGA & $6(21 \%)$ & 0 \\
\hline & Penta D & $4(14 \%)$ & 0 \\
\hline & Penta E & $5(18 \%)$ & 0 \\
\hline & TH01 & $19(68 \%)$ & $2(13 \%)$ \\
\hline & TPOX & $2(7 \%)$ & 0 \\
\hline & vWA & 15 (54\%) & $2(13 \%)$ \\
\hline \multirow[t]{7}{*}{ DIP-STR } & rs2308142-STR & $15(54 \%)$ & $2(13 \%)$ \\
\hline & rs34212659-STR & $13(46 \%)$ & 0 \\
\hline & rs35032587-STR & $9(32 \%)$ & 0 \\
\hline & rs60194384-STR & $12(43 \%)$ & 0 \\
\hline & rs $111478323-S T R$ & $7(25 \%)$ & 0 \\
\hline & rs $142543564-S T R$ & $9(32 \%)$ & 0 \\
\hline & rs145423446-STR & $12(43 \%)$ & $1(7 \%)$ \\
\hline
\end{tabular}

but, as reflected in $p$ values, it was close to statistical significance in both groups of twin pregnancies. Similarly, no correlation between the fraction of male DNA in plasma cfDNA and the number of DIP-STR markers that showed the presence of at least one fetal allele was seen in twin pregnancies with two male fetuses $\left(R^{2}=.28, p=.12\right)$ and in twin pregnancies with one male fetus $\left(R^{2}=.03, p=.79\right)$.

\section{Discussion}

Zygosity of twins is frequently determined in the postnatal period to satisfy the parents' curiosity, and also for the purpose of potential tissue and organ donation, and to predict the risk of genetic diseases (Brown, 2015; Craig et al., 2015). Determination of zygosity of twins is possible after birth on the basis of the sex of twins, pregnancy chorionicity, dermatoglyphs, serological examination and DNA typing (Adamski et al., 2016; Derom et al., 1985; Derom et al., 2001). As sex and chorionicity of the twin pregnancy may also be established in the ultrasound prenatal examination, it is possible to assess zygosity before delivery as well.

It is assumed that it is more important for the course of twin pregnancy to know its chorionicity than zygosity (Bajoria \& Kingdom, 1997; Carroll et al., 2005). Diagnosis of chorionicity is performed routinely by high-resolution ultrasound examination based on intertwin membrane thickness and the presence or absence of lambda or $\mathrm{T}$ sign between 10 and 14 weeks (Sepulveda et al., 1996). However, in the midpregnancy, this evaluation becomes unclear, and there are patients who miss their early pregnancy scan. Moreover, it is not always possible to ascertain chorionicity by ultrasound examination due to technical limitations, intrauterine crowding of fetuses, reduced amount of amniotic fluid and obesity of a pregnant woman (Lee et al., 
2010). Prediction of risk for twin pregnancy is even more complicated by false positive ultrasound diagnoses of dichorionicity (Yamashita et al., 2015) and by such phenomena as fusion of chorions in DZ pregnancy or division of a chorion in $\mathrm{MZ}$ pregnancy (Arabin \& van Eyck, 2001; Benson \& Doubilet, 1991, 2000; Dalton \& Dudley, 1989; Hickey \& Goldberg, 1996;). In all the aforementioned cases, a DNA test to determine pregnancy zygosity may have a prognostic value (Appelman et al., 1994; Norton et al., 1997). Although circa 50\% of DZ pregnancies may be identified by ultrasound examination due to opposite sex of twins, there are known a number of cases of sex-discordant MZ twins (Bohec et al., 2010; Wachtel et al., 2000). Diagnosis of dizygosity indicates an extremely low risk for TTTS, which affects as much as $5-10 \%$ of MZ pregnancies (Simpson \& Miller, 2018) and was reported only in several cases of DZ pregnancies in the world (Chen et al., 2013; McNamara et al., 2016). Furthermore, observation of malformations in only one twin with confirmed dizygosity of pregnancy could restrict invasive diagnostic procedures to only one fetus.

Initially, prenatal determination of zygosity in multiple pregnancies based on analysis of DNA polymorphism was conducted with the use of biological material collected during amniocentesis, chorionic villus biopsy or cordocentesis (Chen et al., 2000; Cirigliano et al., 2003; Fang et al., 2004; Kovacs et al., 1988; Levy et al., 2002). In order to determine zygosity on the basis of DNA typing of such samples, molecular probes were used to analyze restriction fragment length polymorphism (Azuma et al., 1989; Kovacs et al., 1988) or polymorphism of sequences of PCR products (Levy et al., 2002). Later, quantitative fluorescent PCR of STR markers was implemented for this purpose (Chen et al., 2000; Cirigliano et al., 2003; Fang et al., 2004). However, amniocentesis, chorionic villus biopsy and cordocentesis are invasive for pregnancy and are characterized by a high risk of complications. New possibilities for diagnosis of pregnancy zygosity have appeared with studies of free fetal DNA circulating in the mother's blood. Smid et al. (2003) performed quantification of the SRY gene located on the $\mathrm{Y}$ chromosome in plasma of pregnant women and showed that the amount of male DNA in cfDNA is correlated with the number of male fetuses. These findings are in accordance with the results of our study based on qPCR of male DNA, which showed that the amount of fetal DNA in plasma of women with twin pregnancies is approximately twice as high as in singleton pregnancies, which confirms the possibility to use cfDNA from maternal plasma in prenatal genetic analysis of twins.

As we have found no studies of pregnancy zygosity testing based on STR polymorphism in cfDNA isolated from plasma of pregnant women, the aim of our study was to analyze the usefulness of microsatellite markers in the diagnosis of zygosity of twin pregnancies. Our preliminary results based on 22 STR loci have shown significant usefulness of STR genotyping in cfDNA of maternal plasma for prenatal diagnosis of zygosity of twin pregnancies. Regarding detection of dizygosity of twin pregnancies, the set of 22 STR markers showed $67 \%$ sensitivity, $100 \%$ specificity and $82 \%$ accuracy. It means that after genotyping of 22 STRs, roughly two-thirds of DZ twin pregnancies may be classified as low-risk twin pregnancies, narrowing the number of cases for strict and frequent ultrasound supervision and reducing costs of prenatal care. Also, as discussed later, it should be noted that accuracy of an assay seems to depend on the number of tested markers. The newest capillary electrophoresis instruments, yet unreleased to the market (e.g., Spectrum CE System from Promega), employ 8-dye technology that roughly doubles the number of markers that may be included in one multiplex PCR system and will allow development of new STR assays with much higher sensitivity for detection of DZ twin pregnancies than the PowerPlex Fusion kit used in our preliminary study.

The majority of cfDNA isolated from the plasma of a pregnant woman is maternal DNA, while the minority component (in this case, fetal DNA) may not be detected by STR typing if it constitutes less than $5 \%$ of the mixture (1:20 ratio; Butler, 2015). As fetal DNA constitutes on the average $3-20 \%$ of the total plasma cfDNA, fetal alleles may remain undetected in analysis of STR polymorphism by quantitative fluorescent PCR. For this reason, our attention was turned to DIP-STR markers, which enable detection of alleles of the minority component (in our case, fetal DNA) in the presence of the majority component (in our case, maternal DNA) even when the ratio of both components is 1:1000 (Castella et al., 2013). Castella et al. (2013) demonstrated the usefulness of genotyping of DIP-STR markers in DNA mixtures also in the case of fetomaternal microchimerism. Our results of DIP-STR polymorphism analysis in plasma samples from women with twin pregnancies showed lower usefulness of the analyzed set of DIP-STR markers in detecting dizygosity of pregnancy (13\% sensitivity, $100 \%$ specificity, 54\% accuracy) in comparison to the PowerPlex Fusion kit. However, statistical analysis revealed no significant differences between the tested STRs and DIP-STRs in capability to diagnose dizygosity of twin pregnancies, which suggests that the higher usefulness of the PowerPlex Fusion kit in comparison with the homemade multiplexes of DIP-STR markers merely results from a higher number of markers included in the PowerPlex Fusion kit (22 STRs vs. 7 DIP-STRs). It should also be noted that our preliminary study was conducted on women up to 41 weeks of gestation, when the fetal DNA content in plasma is the highest. It is possible that limitation of the studied group to pregnant women in early pregnancy, when fetal DNA constitutes only $3-10 \%$ of plasma cfDNA, would show an advantage of DIP-STR markers over typical microsatellites.

Although correlation between the fraction of male DNA (corresponding to the fraction of fetal DNA in twin pregnancies without female fetuses) and the number of detected fetal alleles was not observed, it was very close to statistical significance in the case of STRs, but not in the case of DIP-STRs. It may result from the fact that in the case of the latter, detection of minority alleles does not depend so strongly on the fraction of fetal DNA as far as DIP-STR alleles may be successfully genotyped even if the minority component (fetal DNA) constitutes much less than $5 \%$ of the DNA mixture (plasma cfDNA). However, these observations were based on only 10 twin pregnancies with two male fetuses and 5 twin pregnancies with one male fetus, so further studies with larger numbers of cases are required to confirm the higher robustness of DIP-STRs in prenatal zygosity testing of twin pregnancies. Nevertheless, $p$ values at the limit of statistical significance for STR markers indicate that detection of twin pregnancy dizygosity by the STR assay is more likely to depend on the fraction of fetal DNA. Thus, sensitivity of the STR assay will grow with gestational age and will be higher if release of maternal cfDNA is prevented; for example, by stabilization of maternal blood cells after sample collection. In our study, blood samples collected in K3-EDTA tubes were used for isolation of plasma cfDNA within $8 \mathrm{~h}$ of sample collection (Barrett et al., 2011), so the impact of maternal cfDNA release on the results seems to be negligible.

Determination of zygosity of twin pregnancies on the basis of cfDNA from plasma of pregnant women is also currently possible 
with the use of massively parallel sequencing (MPS; Qu et al., 2013; Zheng et al., 2013). However, this method requires relatively large amounts of cfDNA, reaching up to $30 \mathrm{ng}$ (Qu et al., 2013), while the amount of DNA obtained from maternal plasma is often scarce (in our study, $10 \mathrm{ng}$ from $200 \mu \mathrm{L}$ of plasma, on average) and would not allow determination of zygosity with the use of MPS in many our patients, even if cfDNA was isolated from $600 \mu \mathrm{L}$ of plasma, as in the study by Zheng et al. (2013). Moreover, MPS is associated with relatively high costs, reaching several hundred US dollars for one patient. On the contrary, a total cost of zygosity testing with the use of our sets of STR or DIP-STR markers does not exceed USD10 for one patient with a twin pregnancy. Furthermore, twin pregnancy zygosity testing by STR and DIP-STR genotyping is very rapid and simple, whereas MPS requires laborious sample processing and advanced bioinformatic analyses. As shown in Figures 1 and 2, interpretation of STR and DIP-STR profiles is straightforward and unequivocal with four alleles detected at one or more STR/DIP-STR markers indicating DZ twins. It should also be emphasized that studies of zygosity involving the MPS method published so far were based only on a few cases of twin pregnancies (eight cases studied by Qu et al., 2013 and four cases studied by Zheng et al., 2013), while our preliminary study was based on 28 twin pregnancies.

A certain limitation of our assays is the risk of a false positive result (false detection of DZ pregnancy) in the case of trisomy resulting from paternal nondisjunction. Therefore, detection of four alleles at STR or DIP-STR markers located on one chromosome, especially on chromosome 21,18 or 13 , should be diagnosed as a result indicating DZ twin pregnancy only if trisomy is excluded by other tests. Detection of four alleles is also possible in MZ twin pregnancy if pregnancy results from in vitro fertilization with egg cell donation. Therefore, diagnosis of zygosity of twin pregnancy should always be preceded by medical history regarding assisted reproduction technology.

Owing to $100 \%$ specificity and lower sensitivity, results of genotyping of STR/DIP-STR markers in plasma cfDNA indicate either that a twin pregnancy is $\mathrm{DZ}$ or that zygosity status is undetermined. Thus, prenatal diagnosis of twin dizygosity does not need to be confirmed after birth.

In summary, relatively high sensitivity, specificity and accuracy of the assays, low DNA input requirements, low costs and simplicity of the analysis make genotyping of STR/DIP-STR markers a useful tool for noninvasive prenatal diagnosis of zygosity of twin pregnancies.

Financial support. This research received no specific grant from any funding agency, commercial or not-for-profit sectors.

\section{Conflict of interest. None.}

Ethical standards. The authors assert that all procedures contributing to this work comply with the ethical standards of the relevant national and institutional committees on human experimentation and with the Helsinki Declaration of 1975, as revised in 2008.

\section{References}

Adamski, P., Ciach, K., Kiełbratowska, B., Szczerkowska, Z., \& Preis, K. (2016). DNA profiling as a method of zygosity determination in multiple pregnancy. Ginekologia Polska, 87, 222-225.

Allyse, M., Sayres, L. C., King, J. S., Norton, M. E., \& Cho, M. K. (2012). Cell-free fetal DNA testing for fetal aneuploidy and beyond: Clinical integration challenges in the US context. Human Reproduction, 27, 3123-3131.
Appelman, Z., Manor, M., Magal, N., Caspi, B., Shohat, M., \& Blickstein, I. (1994). Prenatal diagnosis of twin zygosity by DNA 'fingerprint' analysis. Prenatal Diagnosis, 14, 307-309.

Arabin, B., \& van Eyck, J. (2001). The role of ultrasound in multiple pregnancy. Twin Research, 4, 141-145.

Azuma, C., Kamiura, S., Nobunaga, T., Negoro, T., Saji, F., \& Tanizawa, O. (1989). Zygosity determination of multiple pregnancy by deoxyribonucleic acid fingerprints. American Journal of Obstetrics and Gynecology, 160, 734-736.

Bajoria, R., \& Kingdom, J. (1997). The case for routine determination of chorionicity and zygosity in multiple pregnancy. Prenatal Diagnosis, 17, 1207-1225.

Baldwin, V. J. (1994). Pathology of multiple pregnancy (1st ed.). New York, NY: Springer-Verlag.

Barrett, A. N., Zimmermann, B. G., Wang, D., Holloway, A., \& Chitty, L. S. (2011). Implementing prenatal diagnosis based on cell-free fetal DNA: Accurate identification of factors affecting fetal DNA yield. PLoS One, 6, e25202.

Benson, C. B., \& Doubilet, P. M. (1991). Ultrasound in/of multiple gestations. Seminars in Roentgenology, 26, 50-62.

Benson, C. B., \& Doubilet, P. M. (2000). Ciąża wielopłodowa. Medycyna Praktyczna, 1, 51-63.

Blickstein, I., Verhoeven, H. C., \& Keith, L. G. (1999). Zygotic splitting after associated reproduction. New England Journal of Medicine, 340, 738-739.

Bohec, C., Douet-Guilbert, N., Basinko, A., Le Bris, M.-J., Marcorelles, P., Audrézet, M.-P., ... De Braekeleer, M. (2010). Difficult diagnosis and management of an heterokaryotypic monochorionic twin pregnancy with discordant fetal sex and 45,X/47,XYY karotypes. Fetal and Pediatric Pathology, 29, 424-430.

Brown, R. (2015). Zygosity testing should be encouraged for all same-sex twins: AGAINST: Benefit of this knowledge should be weighed against the potential pitfalls. British Journal of Obstetrics and Gynaecology, 122, 1641.

Butler, J. M. (2012). Advanced topics in forensic DNA typing: Methodology (1st ed.). Waltham, MA: Elsevier.

Butler, J. M. (2015). Advanced topics in forensic DNA typing: Interpretation (1st ed.). Kidlington, UK: Elsevier.

Campbell, D. M. (2000). Ciąża mnoga - epidemiologia. Wiadomości Położniczo-Ginekologiczne, 3, 224-239.

Carroll, S. G., Tyfield, L., Reeve, L., Porter, H., Soothill, P., \& Kyle, P. M. (2005). Is zygosity or chorionicity the main determinant of fetal outcome in twin pregnancies? American Journal of Obstetrics and Gynecology, 193, 757-761.

Castella, V., Gervaix, J., \& Hall, D. (2013). DIP-STR: Highly sensitive markers for the analysis of unbalanced genomic mixtures. Human Mutation, 34, 644-654.

Cereda, G., Biedermann, A., Hall, D., \& Taroni, F. (2014). An investigation of the potential of DIP-STR markers for DNA mixture analyses. Forensic Science International: Genetics, 11, 229-240.

Chen, C. P., Chern, S. R., \& Wang, W. (2000). Rapid determination of zygosity and common aneuploidies from amniotic fluid cells using quantitative fluorescent polymerase chain reaction following genetic amniocentesis in multiple pregnancies. Human Reproduction, 15, 929-934.

Chen, K., Chmait, R. H., Vanderbilt, D., Wu, S., \& Randolph, L. (2013). Chimerism in monochorionic dizygotic twins: Case study and review. American Journal Of Medical Genetics Part A, 161A, 1817-1824.

Cirigliano, V., Cañadas, P., Plaja, A., Ordoñez, E., Mediano, C., Sánchez, A., \& Farrán, I. (2003). Rapid prenatal diagnosis of aneuploidies and zygosity in multiple pregnancies by amniocentesis with single insertion of the needle and quantitative fluorescent PCR. Prenatal Diagnosis, 23, 629-633.

Craig, J. M., Segal, N. L., Umstad, M. P., Cutler, T. L., Keogh, L. A., Hopper, J. L., .. Harris, J. R. (2015). Zygosity testing should be encouraged for all same-sex twins: FOR: A genetic test is essential to determine zygosity. British Journal of Obstetrics and Gynaecology, 122, 1641.

Dalton, M., \& Dudley, D. (1989). The ultrasonographic prediction of chorionicity in twin gestation. American Journal of Obstetrics and Gynecology, 160, $557-561$. 
Derom, C., Bakker, E., Vlietinck, R., Derom, R., van den Berghe, H., Thiery, M., ... Pearson, P. L. (1985). Zygosity determination in newborn twins using DNA variants. Journal of Medical Genetics, 22, 279-282.

Derom, C., Derom, R., Vlietinck, R., Vanden Berghe, H., \& Thiery, M. (1987). Increased monozygotic twinning rate after ovulation induction. The Lancet, 1, 1236-1238.

Derom, R., Bryan, E., Derom, C., Keith, L., \& Vlietinck, R. (2001). Twins, chorionicity and zygosity. Twin Research, 4, 134-136.

Doyle, P. (1996). The outcome of multiple pregnancy. Human Reproduction, 11, 110-117.

Edwards, R., Mettler, L., \& Walters, D. (1986). Identical twins and in vitro fertilization. Journal of In Vitro Fertilization and Embryo Transfer: IVF, 3, 114-117.

Evans, P. C., Lambert, N., Maloney, S., Furst, D. E., Moore, J. M., \& Nelson, J. L. (1999). Long-term fetal microchimerism in peripheral blood mononuclear cell subsets in healthy women and women with scleroderma. Blood, 93, 2033-2037.

Faas, B. H., de Ligt, J., Janssen, I., Eggink, A. J., Wijnberger, L. D., van Vugt, J. M., . . Geurts van Kessel, A. (2012). Non-invasive prenatal diagnosis of fetal aneuploidies using massively parallel sequencing-by-ligation and evidence that cell-free fetal DNA in the maternal plasma originates from cytotrophoblastic cells. Expert Opinion on Biological Therapy, 12, S19-S26.

Fang, Q., An, N., Wu, X. Y., Liu, Q. L., \& Feng, S. H. (2004). Short tandem repeat polymerase chain reaction used in prenatal diagnoses of the zygosity and common chromosomal trisomies in multiple pregnancies. National Medical Journal of China, 84, 667-670.

Flori, E., Doray, B., Gautier, E., Kohler, M., Ernault, P., Flori, J., \& Costa, J. M. (2004). Circulating cell-free fetal DNA in maternal serum appears to originate from cyto- and syncytio-trophoblastic cells. Case report. Human Reproduction, 19, 723-724.

Gall, S. A. (1996). Multiple pregnancy and delivery. St. Louis, MO: Mosby.

Gill, P., Kimpton, C., d'Aloja, E., Andersen, J. F., Bar, W., Brinkmann, B.,

Stenersen M. (1994). Report of the European DNA profiling group (EDNAP) - Towards standardization of short tandem repeat (STR) loci. Forensic Science International, 65, 51-59.

Golan, A., Amit, A., Baram, A., \& David, M. P. (1981). Unusual cord intertwinning in monoamniotic twins. The Australian and New Zealand Journal of Obstetrics and Gynaecology, 22, 165-167.

Hickey, J., \& Goldberg, F. (1996). Ultrasound review of obstetrics and gynecology (1st ed.). Philadelphia, PA: Lippincott Williams \& Wilkins.

Hochstenbach, R., Nikkels, P. G., Elferink, M. G., Oudijk, M. A., van Oppen, C., van Zon, P., ... Page-Christiaens, G. C. M. L. (2015). Cell-free fetal DNA in the maternal circulation originates from the cytotrophoblast: Proof from a unique case. Clinical Case Reports, 3, 489-491.

Jobling, M. A., \& Gill, P. (2004). Encoded evidence: DNA in forensic analysis. Nature Reviews Genetics, 5, 739-751.

Kovacs, B., Shahbahrami, B., Platt, L. D., \& Comings, D. E. (1988). Molecular genetic prenatal determination of twin zygosity. Obstetrics and Gynecology, 72, 954-956.

Lahiri, D. K., \& Nurnberger, J. I. (1991). A rapid non-enzymatic method for the preparation of HMW DNA from blood for RFLP studies. Nucleic Acids Research, 19, 5444.

Landy, H. J., \& Nies, B. M. (1995). The vanishing twin. In L. G. Keith, E. Papiernik, D. M. Keith, \& B. Luke (Eds.), Multiple pregnancy: Epidemiology, gestation and perinatal outcome (1st ed., pp. 59-71). New York, NY: The Parthenon Publishing Group.

Lee, A. K., Oh, K. J., Lee, S. M., Kim A, \& Jun, J. K. (2010). The frequency and clinical significance of twin gestations according to zygosity and chorionicity. Twin Research and Human Genetics, 13, 609-619.

Levy, R., Mirlesse, V., Jacquemard, F., \& Daffos, F. (2002). Prenatal diagnosis of zygosity by fetal DNA analysis, a contribution to the management of multiple pregnancies: A series of 31 cases. Fetal Diagnosis and Therapy, 17, 339-342.

Lo, Y. M. (2008). Fetal nucleic acids in maternal plasma. Annals of the New York Academy of Sciences, 1137, 140-143.

Lo, Y. M., Hjelm, N. M., Fidler, C., Sargent, I. L., Murphy, M. F., Chamberlain, P. F., ... Wainscoat, J. S. (1998). Prenatal diagnosis of fetal
RhD status by molecular analysis of maternal plasma. New England Journal of Medicine, 339, 1734-1738.

Lo, Y. M., Tein, M. S., Lau, T. K., Haines, C. J., Leung, T. N., Poon, P. M., . . . Hjelm, N. M. (1998). Quantitative analysis of fetal DNA in maternal plasma and serum: Implications for noninvasive prenatal diagnosis. American Journal of Human Genetics, 62, 768-775.

Lun, F. M., Tsui, N. B., Chan, K. C., Leung, T. Y., Lau, T. K., Charoenkwan, P.,

Lo, Y. M. (2008). Noninvasive prenatal diagnosis of monogenic diseases by digital size selection and relative mutation dosage on DNA in maternal plasma. Proceedings of the National Academy of Sciences of the United States of America, 105, 19920-19925.

Machin, G. A. (1993). Conjoined twins: Implications for blastogenesis. Birth Defects: Original Article Series, 29, 141-179.

McNamara, H. C., Kane, S. C., Craig, J. M., Short, R. V., \& Umstad, M. P. (2016). A review of the mechanisms and evidence for typical and atypical twinning. American Journal of Obstetrics and Gynecology, 214, $172-191$.

Monteagudo, A., Timor-Tritsch, I. E., \& Sharma, S. (1994). Early and simple determination of chorionic and amniotic type of multifetal gestations in the first fourteen weeks by high-frequency transvaginal ultrasonography. American Journal of Obstetrics and Gynecology, 170, 824-829.

Moretti, T. R., Baumstark, A. L., Defenbaugh, D. A., Keys, K. M., Smerick, J. B., \& Budowle, B. (2001). Validation of short tandem repeats (STRs) for forensic usage: Performance testing of fluorescent multiplex STR systems and analysis of authentic and simulated forensic samples. Journal of Forensic Sciences, 46, 647-660.

Mujezinovic, F., \& Alfirevic, Z. (2007). Procedure-related complications of amniocentesis and chorionic villous sampling: A systematic review. Obstetrics and Gynecology, 110, 687-694.

Norton, M. E., D'Alton, M. E., \& Bianchi, D. W. (1997). Molecular zygosity studies aid in the management of discordant multiple gestations. Journal of Perinatology, 17, 202-207.

Oldoni, F., Castella, V., \& Hall, D. (2015). A novel set of DIP-STR markers for improved analysis of challenging DNA mixtures. Forensic Science International: Genetics, 19, 156-164.

Pison, G., \& D'Addato, A. V. (2006). Frequency of twin births in developed countries. Twin Research and Human Genetics, 9, 250-259.

Pison, G., Monden, C., \& Smits, J. (2015). Twinning rates in developed countries: Trends and explanations. Population and Development Review, $41,629-649$.

Qu, J. Z. Z., Leung, T. Y., Jiang, P., Liao, G. J. W., Cheng, Y. K. Y., Sun, H., . . Lo D. (2013). Noninvasive prenatal determination of twin zygosity by maternal plasma DNA analysis. Clinical Chemistry, 59, 427-435.

Sepulveda, W., Sebire, N. J., Hughes K, Odibo A., \& Nicolaides, K. H. (1996). The lambda sign at 10-14 weeks of gestation as a predictor of chorionicity in twin pregnancies. Ultrasound in Obstetrics and Gynecology, 7, 421-423.

Simpson, L. L., \& Miller, R. S. (2018). Twin-twin transfusion syndrome. In J. A. Copel, M. E. D'Alton, H. Feltovich, E. Gratacós, D. Krakow, A. O. Odibo, L. Platt, \& B. Tutschek (Eds.), Obstetric imaging: Fetal diagnosis and care (2nd ed., pp. 651-659). Philadelphia, PA: Elsevier.

Smid, M., Galbiati, S., Vassallo, A., Gambini, D., Ferrari, A., Restagno, G., Cremonesi, L. (2003). Fetal DNA in maternal plasma in twin pregnancies. Clinical Chemistry, 49, 1526-1528.

Smits, J., \& Monden, C. (2011). Twinning across the developing world. PLoS One, 6, e25239.

Tjoa, M. L., Cindrova-Davies, T., Spasic-Boskovic, O., Bianchi, D. W., \& Burton, G. J. (2006). Trophoblastic oxidative stress and the release of cell-free feto-placental DNA. American Journal of Pathology, 169, 400-404.

Vallone, P. M., \& Butler, J. M. (2004). AutoDimer: A screening tool for primerdimer and hairpin structures. BioTechniques, 37, 226-231.

Wachtel, S. S., Somkuti, S. G., \& Schinfeld, J. S. (2000). Monozygotic twins of opposite sex. Cytogenetics and Cell Genetics, 91, 293-295.

Wang, E., Batey, A., Struble, C., Musci, T., Song, K., \& Oliphant, A. (2013). Gestational age and maternal weight effects on fetal cell-free DNA in maternal plasma. Prenatal Diagnosis, 33, 662-666.

Wimalasundera, R., \& Fisk, N. (2002). In-vitro fertilization and risk of multiple pregnancy. The Lancet, 360, 414. 
Wright, C. F., \& Burton, H. (2008). The use of cell-free fetal nucleic acids in maternal blood for non-invasive prenatal diagnosis. Human Reproduction Update, 15, 139-151.

Yamashita, A., Ishii, K., Hidaka, N., Yonetani, N., Hayashi, S., Takeuchi, M., \& Mitsuda, N. (2015). Monochorionic monozygotic twin pregnancy complicated with twin-twin transfusion syndrome presenting with an obvious lambda sign in the first trimester. Fetal Diagnosis and Therapy, 37, 154-156.
Ying, L., Zimmermann, B., Rusterholz, C., Kang, A., Holzgreve, W., \& Hahn, S. (2004). Size separation of circulatory DNA in maternal plasma permits ready detection of fetal DNA polymorphisms. Clinical Chemistry, 50, 1002-1011.

Zheng, J., Xu, Ch., Guo, J., Wei, Y., Ge, H., Li, X., ... Jiang, H. (2013). Effective noninvasive zygosity determination by maternal plasma target region sequencing. PLoS One, 8, e65050. 